\title{
Justin DANIEL (dir.), Les îles caraibes modèles politiques et stratégies de développement
}

\section{Alain Charier}

\section{(2) OpenEdition}

Édition électronique

URL : http://journals.openedition.org/plc/783

DOI : $10.4000 /$ plc.783

ISSN : 2117-5209

Éditeur

L'Harmattan

\section{Édition imprimée}

Date de publication : 1 janvier 1997

Pagination : 228-233

ISSN : 1279-8657

\section{Référence électronique}

Alain Charier, « Justin DANIEL (dir.), Les îles caraïbes modèles politiques et stratégies de développement », Pouvoirs dans la Caraïbe [En ligne], Spécial | 1997, mis en ligne le 01 avril 2011, consulté le 22

septembre 2020. URL : http://journals.openedition.org/plc/783 ; DOI : https://doi.org/10.4000/plc.783

Ce document a été généré automatiquement le 22 septembre 2020.

(c) Pouvoirs dans la Caraïbe 


\title{
Justin DANIEL (dir.), Les îles caraibes modèles politiques et stratégies de développement
}

\author{
Alain Charier
}

\section{RÉFÉRENCE}

Justin DANIEL (dir.), Les îles caraibes modèles politiques et stratégies de développement.

Paris : Fayard, 1997.

1 Cet ouvrage est né d'une collaboration entre chercheurs de la Caraïbe, d'Europe et des Etats-Unis ayant 1'ambition avouée de diffuser largement des travaux souvent épars sur une région rarement considérée dans sa globalité. Les contributions présentées dessinent la Caraïbe insulaire dans la diversitéde ses statuts politiques (Etats dépendants et territoires liés à une métropole), de ses régimes politiques (démocraties consolidées ou en voie de consolidation) et de ses cultures (sociétés anglophones, franco-créolophones, hispano-phones).

Quelques préoccupations fondamentales charpentent l'ensemble : réévaluation de la théorie fonctionnaliste de la dépendance à la lumière de la réhabilitation des acteurs locaux (Etats, société civile), rôle de la culture et de l'identité comme productrices de sens auprès de populations confrontées à de nouvelles données politiques, économiques et sociales et même (N.C. Duncan) propositions de solutions adaptées à celles-ci.

3 Les singularités de 1'ensemble insulaire sont d'emblée mises en avant (J. Daniel) et notamment sa relative réussite sur le terrain des pratiques démocratiques (à l'exception d'Haïti) et de la résolution pacifique des conflits à laquelle s'oppose un développement économique plus difficile et souvent cahotique.

4 La Caraïbe n'échappe pas pour autant aux conséquences de la mondialisation: épuisement des stratégies de développement économique portées par l'Etat, crise d'une 
démocratie désormais incapable d'améliorer le niveau de vie de ses citoyens, tensions ethniques (re)naissantes. A partir de ce constat J. Daniel envisage quatre débats pouvant permettre de recomposer des modèles désormais dévalués, deux sont communs à maintes régions périphériques (la réévaluation des institutions politiques et la prise en compte de l'essor de la " politique par le bas») alors que les deux autres peuvent apparaître comme plus prégnants dans l'espace insulaire (reconstruction d'une identité régionale, débat sur la créolisation des modèles politiques).

5 La suite du développement met clairement en lumière l'interpénétration de ces quatre débats. C'est ainsi que le rôle grandissant joué par les Organisations non gouvernementales dans la Caraïbe, en même temps qu'il affaiblit les institutions traditionnelles, contribue au renforcement des manifestations de la culture populaire et l'émergence d'une identité régionale « hors diplomatie ».

6 La conclusion de J. Daniel se veut raisonnablement optimiste. Insistant sur le rôle maintenu de l'État dans la résolution des conflits (pour peu qu'il sache intégrer les nouveaux acteurs) elle ne dissimule pas pour autant les menaces qui pèsent sur la région notamment 1'hégémonie renforcée (au travers de 1'ALENA) des Etats-Unis et l'emprise croissante du trafic de drogue et du blanchiment de capitaux qui lui est lié.

7 Le premier groupe de contributions rassemble sous le titre générique de "Modèles institutionnels et trajectoires politiques " des travaux consacrés à 1'évolution des systèmes politiques présents dans la Caraïbe et liés aux modèles métropolitains anglais, français et nord-américain.

8 Anthony Payne (Adaptation et ajustement du système de Westminster. L'ordre politique dans la Caraïbe anglophone) revient sur les caractéristiques et la genèse du système politique en vigueur dans les anciennes colonies britanniques. L'auteur insiste sur la solidité de celui-ci aujourd'hui malgré son élitisme et son autoritarisme originaires. Cependant si l'absence de résultats économiques tangibles dans 1'avenir venait à se confirmer les fortes tensions sociales qui en résulteraient pourraient le remettre en cause.

9 Fred Reno (La créolisation des modèles politico-institutionnels métropolitains) défend la théorie selon laquelle le modèle politique métropolitain importé n'a jamais été en fait rigoureusement appliqué mais a été dès l'origine perverti par le système hérité de la plantation et irrigué par la culture créole (notamment au travers des pratiques clientélistes). L'auteur appuie sa démonstration sur des exemples tirés des évolutions observées dans les Départements d'Outre-Mer français, à Barbade, Trinidad et à la Jamaïque.

10 Aáron. G. Ramos (Porto Rico et les Etats-Unis : la crise du compromis territorial) met en perspective les multiples tensions et contradictions qui peuplent l'espace politique du Commonwealth nord-américain: rôle économique de 1'Etat discuté, enjeu permanent du statut, positionnement vis à vis des évolutions de l'attitude - désormais plus ouverte - des Etats-Unis, érosion de l'Etat associé lui-même. Pour l'auteur il est évident que dans l'avenir les stratégies de développement prendront le pas sur les questions constitutionnelles.

11 La seconde partie de l'ouvrage pose aux travers de quatre textes et sous la formule "Enjeux, stratégies et contraintes" le problème de la difficile relation entre affirmation démocratique et développement économique. 
12 Rosario Espinal (Développement et démocratisation en République dominicaine) nous dépeint les redoutables défis qui assaille une société dans laquelle l'État est étendu mais faible, où la marginalisation des syndicats a entrainé un renouveau de la violence lors des conflits sociaux, où une démocratie encore en processus de consolidation n'a pas encore démontré sa volonté de rupture avec les anciens personnels et les pratiques douteuses et où, enfin, la crise de la dette se fait durement sentir.

13 Fred Constant (Démocratie et développement à la Jamaïque : enjeux, stratégies et contraintes) démontre la capacité d'adaptation des deux principaux partis politiques de cette nation qui ont su faire évoluer leurs positions en matière de développement en fonction des contraintes extérieures, pour après s'être longuement opposés, se retrouver aujourd'hui autour d'un consensus vidé de références idéologiques. Le revers d'une telle évolution a été l'effondrement du système de contrôle clientéliste qui en cas d'échec économique pourrait, selon l'auteur, aboutir à une solution autoritaire.

14 Justin Daniel (Développement et compétition politique : vers une mutation du modèle portoricain?) revient sur le rôle qu'a tenu l'État populiste dans un domaine économique où il a du mal aujourd'hui à situer son action alors que les organisations de la société civile, malgré leur dynamisme dans certains domaines, n'arrivent pas à contester le rôle prééminent des partis. La question du statut du territoire ayant tendance quand à elle a passer au second plan.

15 Neville Duncan (Ajustement structurel et crise de légitimité dans la Caraïbe anglophone : quelques propositions de réforme) adopte une attitude offensive puisqu'il n'hésite pas à proposer un certain nombre de réformes allant dans le sens d'une « good governance ».

16 Selon lui trois préoccupations majeures doivent guider ces ajustements : la recherche d'une meilleure articulation entre le système politique et les réalités économiques, une prise en compte des cultures locales et un plus grand souci de garantir la cohésion sociale.

17 La dernière partie du livre (Cultures politiques) aborde les problèmes posés par les systèmes de représentation du politique dans la Caraïbe et les expressions sociales et ethniques de ceux-ci.

18 Denis-Constant Martin (Culture politique et développement dans les Caraïbes du Commonwealth : Jamaïque, Barbade, Trinidad et Tobago) après un retour sur le concept même de Culture politique, aborde le processus vécu dans les territoires indiqués cidessus avant d'aboutir à la crise actuelle. L'auteur souligne la plus grande fragilité des systèmes politiques vis à vis de l'opinion alors que les systèmes économiques moins lisibles seraient davantage épargnés. Cette contribution aborde la possibilité de restituer - référence rare dans l'ensemble de l'ouvrage - la situation de la Caraïbe dans un cadre comparatif englobant l'Amérique Latine voisine.

19 John Laguerre (Culture et politique en Jamaïque et à Trinidad: une perspective comparative) démontre comment les mesures d'austérité commandées par la crise ont affecté de façon différente les diverses ethnies à Trinidad et ranimé les problèmes raciaux à la Jamaïque. Il souligne cependant le rôle de l'influence culturelle des EtatsUnis qui imposent les mêmes références aux divers groupes.

20 Robert E. Maguire (Nouveaux acteurs et institutions établies : la mobilisation par le bas en Haïti) aborde la situation particulière d'Haïti, seul Etat de la région à avoir subi une dictature dans la période récente et ou 1'Etat s'est construit contre la nation. Cette 
contribution est également celle qui met le plus l'accent sur le rôle joué désormais par les ONG et les organisations de la société civile en général dans l'invention d'une tradition démocratique.

21 Le texte de Michel Giraud (Des usages politiques et politologiques de la culture dans les études caribéennes) se veut une réponse à la thèse de la créolisation défendue par Fred Reno et vient clore l'ouvrage. Sans doute ces deux contributions auraient-elles pu figurer, à notre sens, à la suite 1'une de l'autre afin d'en comparer plus aisément les arguments. Selon M. Giraud les éléments décrits sous le terme de "créolisation » ne sont ni univoques, ni exclusifs et c'est à partir des productions sociales des cultures créoles que l'on pourra renouveler l'étude politologique de la réalité de la Caraïbe.

Cet ouvrage par la multiplicité de ses approches qui ne nuit en rien à la cohésion de l'ensemble, par la diversité - voire l'opposition - des points de vue exprimés et par le large éventail des réalités sociales, culturelles et nationales décrites est incontestablement un outil précieux pour la compréhension d'une région rarement abordée dans sa globalité. Au-delà de la Caraïbe, il ouvre des pistes de recherche sur les défis multiples engendrés par la mondialisation. 